Preis/Sagan (Hrsg.)

Europäisches Arbeitsrecht 



\title{
Europäisches Arbeitsrecht
}

\section{Grundlagen · Richtlinien Folgen für das deutsche Recht}

\author{
herausgegebenvon \\ Prof. Dr. Dr. h.c. Ulrich Preis \\ Dr. Adam Sagan, MJur (Oxon) \\ bearbeitet von
}

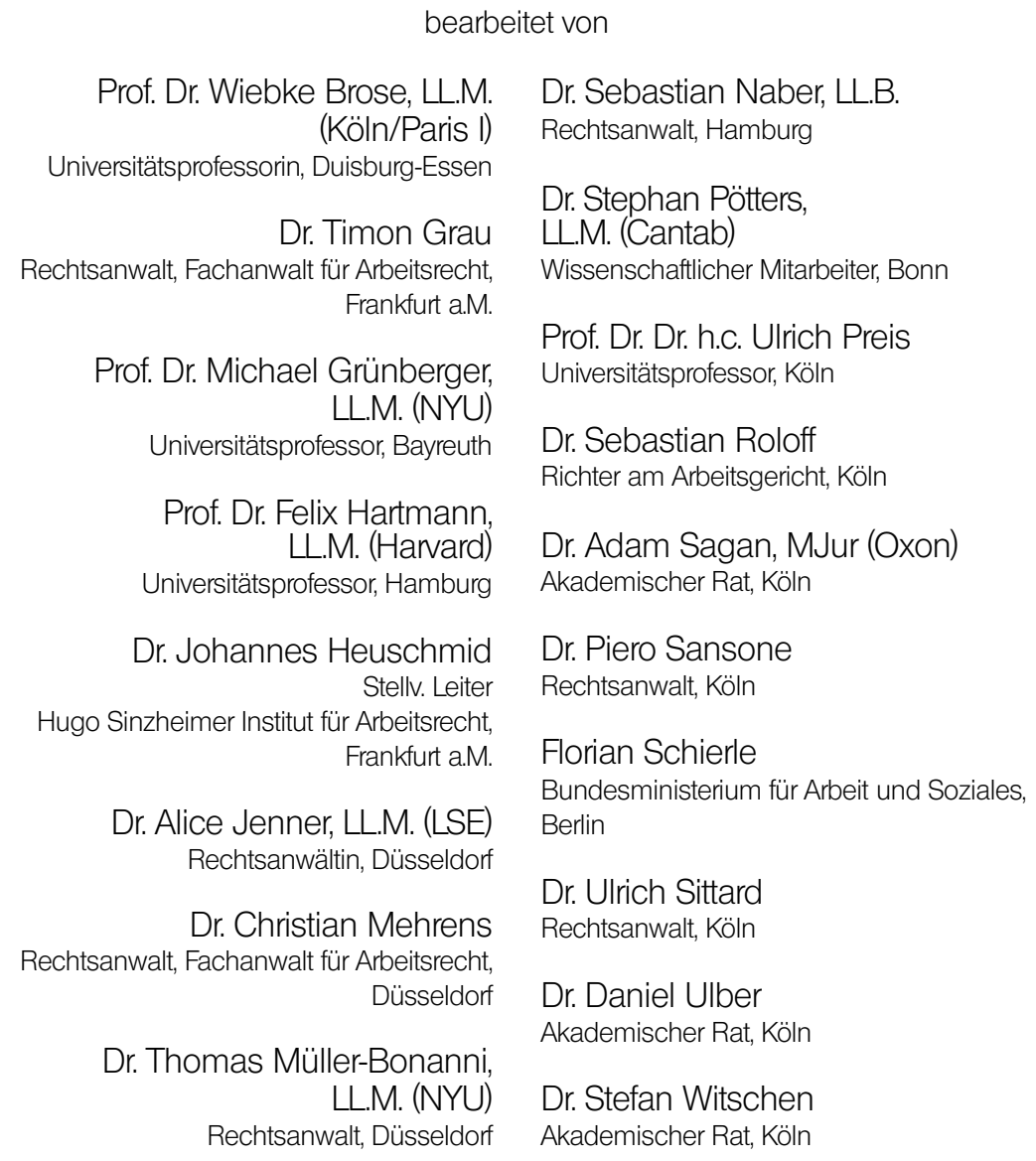




\section{Zitierempfehlung:}

Verfasser in Preis/Sagan,

Europäisches Arbeitsrecht, §... Rz. ...

\section{Bibliografische Information \\ der Deutschen Nationalbibliothek \\ Die Deutsche Nationalbibliothek verzeichnet diese Publikation in der Deutschen Nationalbibliografie; detaillierte bibliografische Daten sind im Internet über http://dnb.d-nb.de abrufbar.}

Verlag Dr. Otto Schmidt KG

Gustav-Heinemann-Ufer 58, 50968 Köln

Tel. 02 21/93738-01, Fax 02 21/93738-943

info@otto-schmidt.de

www.otto-schmidt.de

ISBN 978-3-504-42048-2

(C) 2015 by Verlag Dr. Otto Schmidt KG, Köln

Das Werk einschließlich aller seiner Teile ist urheberrechtlich geschützt. Jede Verwertung, die nicht ausdrücklich vom Urheberrechtsgesetz zugelassen ist, bedarf der vorherigen Zustimmung des Verlages. Das gilt insbesondere für Vervielfältigungen, Bearbeitungen, Übersetzungen, Mikroverfilmungen und die Einspeicherung und Verarbeitung in elektronischen Systemen.

Das verwendete Papier ist aus chlorfrei gebleichten Rohstoffen hergestellt, holz- und säurefrei, alterungsbeständig und umweltfreundlich.

Einbandgestaltung: Jan P. Lichtenford, Mettmann

Satz: Schäper, Bonn

Druck und Verarbeitung: Kösel, Krugzell

Printed in Germany 